University of Wollongong

Research Online

Faculty of Engineering - Papers (Archive)

Faculty of Engineering and Information

Sciences

$1-1-2007$

\title{
Texture evolution during annealing of warm rolled cr-containing low carbon steels
}

E V. Pereloma

University of Wollongong, elenap@uow.edu.au

Azdiar A. Gazder

University of Wollongong, azdiar@uow.edu.au

John J. Jonas

McGill University, john.jonas@mcgill.ca

Chris H. J. Davies

Monash University, chris.davies@eng.monash.edu.au

Follow this and additional works at: https://ro.uow.edu.au/engpapers

Part of the Engineering Commons

https://ro.uow.edu.au/engpapers/1198

\section{Recommended Citation}

Pereloma, E V.; Gazder, Azdiar A.; Jonas, John J.; and Davies, Chris H. J.: Texture evolution during annealing of warm rolled cr-containing low carbon steels 2007, 295-300.

https://ro.uow.edu.au/engpapers/1198

Research Online is the open access institutional repository for the University of Wollongong. For further information contact the UOW Library: research-pubs@uow.edu.au 


\title{
Texture Evolution during Annealing of Warm Rolled Cr-containing Low Carbon Steels
}

\author{
Elena V. Pereloma ${ }^{1, a}$, Azdiar Gazder ${ }^{2, b}$, John J. Jonas ${ }^{3, c}$ and \\ Chris H.J. Davies ${ }^{2, d}$ \\ ${ }^{1}$ School of Mechanical, Materials and Mechatronics Engineering, University of Wollongong, Northfields \\ Avenue, Wollongong, NSW 2522, Australia \\ ${ }^{2}$ Department of Materials Engineering, Monash University, VIC 3800, Australia \\ ${ }^{3}$ Department of Materials Engineering, McGill University, Montreal, H3A 2B2, Canada

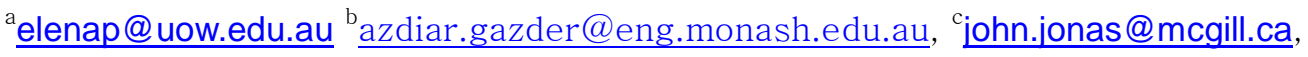 \\ dchris.davies@eng.monash.edu.au
}

Keywords: Cr alloyed low carbon steel, warm rolling, annealing, texture, electron back scattering diffraction

\begin{abstract}
Two low carbon steels alloyed with $0.48 \mathrm{wt} \%$ and $0.78 \mathrm{wt} \% \mathrm{Cr}$ were warm rolled to $65 \%$ reduction at $640^{\circ} \mathrm{C}$. Annealing was carried out at $710^{\circ} \mathrm{C}$ to achieve a range of recrystallized volume fractions up to $100 \%$. Texture analysis was performed by X-ray diffraction and Electron Back Scattering Diffraction. During the initial stages of recrystallization, more recrystallized grains nucleated at shear bands than at grain boundaries in the $0.48 \mathrm{wt} \% \mathrm{Cr}$ steel, whereas this was not the case in the $0.78 \mathrm{wt} \% \mathrm{Cr}$ steel. This is associated with a decrease in the propensity to form shear bands due to the lower amount of $\mathrm{C}$ in solid solution in the high-Cr steel. Additionally, the nuclei showed a preference to develop the same fiber as the deformed region within which they nucleated. In both steels, an increase in the annealing time led to the deterioration of the ND (or $\gamma$ ) -fiber and a strengthening of both the RD (or $\alpha$ ) -fiber and Goss component. In the fully recrystallized samples, the ND component was somewhat stronger in the steel with the higher Cr content.
\end{abstract}

\section{Introduction}

A high mean $r$-value, which reflects good formability, is one of the requisite properties of steel sheet products for deep drawing applications. However, in warm rolled low carbon steels there are phenomena which confound the development of the desirable $\{111\}$ annealing texture component parallel to the rolling plane (ND or $\gamma$-fiber) [1,2]. Under warm rolling conditions, the in-grain shear bands, which are inclined at $20^{\circ}-35^{\circ}$ to the rolling direction, are effective in promoting a strong $\{111\}$ annealing texture, but in the presence of a significant amount of solute carbon dynamic strain ageing limits the formation of the in-grain shear bands. This is the case for low carbon steel, which displays unusually high rate sensitivities in the warm rolling temperature range and contains a low density of shear bands [3], a weak $\{111\}$ recrystallization component and low mean $r$-values. The addition of carbide-forming elements (such as $\mathrm{Cr}$ ) leads to an increase in the number of grains containing shear bands after warm rolling, a change that can improve the formability of the steel 
after annealing [3-6]. The texture evolution during annealing develops from preferential nucleation sites and/or orientated growth, and in warm rolled steel, a variety of nucleation sites for recrystallized grains are available, such as initial grain boundaries, deformation bands, the intersection of shear bands and microbands, and precipitates [7-9]. The present work focuses on the comparison of texture evolution during annealing in two low carbon steels alloyed with 0.48 wt\% and $0.78 \mathrm{wt} \% \mathrm{Cr}$. In particular, attention is given to the characterization of recrystallized grains, their location and orientation.

\section{Experimental}

Two steels containing $0.04 \mathrm{C}-0.35 \mathrm{Mn}-0.48 \mathrm{Cr}-0.036 \mathrm{Al}-0.012 \mathrm{~N}$ and $0.022 \mathrm{C}-0.15 \mathrm{Mn}-0.035 \mathrm{Al}-$ $0.038 \mathrm{~N}--.78 \mathrm{Cr}$ (wt\%), were used in this study. Hereafter, they will be referred to as the low-Cr and high-Cr steels. After reheating for $30 \mathrm{~min}$ at $1050^{\circ} \mathrm{C}$, all the samples were warm rolled at $640^{\circ} \mathrm{C}$ (average strain rates of $30 \mathrm{~s}^{-1}$ ) to reductions of $65 \%$ in a single pass on the EMR-CANMET pilot mill in Ottawa, Ontario. Slices of the deformed steels (taken from the TD and ND planes) were annealed in an open atmosphere furnace at $710^{\circ} \mathrm{C}$ for various times in order to obtain increasing volume fractions of recrystallized grains. A thermocouple was attached to the sample to monitor the temperature during annealing. The samples were covered with alumina powder to reduce oxidation. The steels were examined by electron back scatter diffraction (EBSD) in a LEO-1530 FEG-SEM fitted with a Nordlys-II ${ }^{\mathrm{TM}}$ EBSD detector. Step sizes of 0.25 and $0.5 \mu \mathrm{m}$ were used. Post-processing of the raw data was undertaken using HKL-Channel 5 software. Bulk texture analysis was performed on $\sim 10 \times 10 \times 3 \mathrm{~mm}^{3}$ samples using a GBC-MMA texture goniometer working at $40 \mathrm{kV}$ and $25 \mathrm{~mA}$ and equipped with a $\mathrm{Cu}-\mathrm{K}_{\alpha}$ anode and a polycapillary beam enhancer. Raw data in the form of incomplete pole figures (PFs) $\left(\chi=0^{\circ}-80^{\circ}\right)$ from the (110), (200), and (211) crystallographic planes were used to calculate the orientation distribution functions (ODFs). The ODFs $\mathrm{f}(\mathrm{g})$ are represented in contour levels of $1.5 \times$ with a maximum intensity of 11.5 . Since cubic crystal and orthorhombic sample symmetries are involved, the textures are presented for the $\phi_{2}=$ $45^{\circ}$ section in $\phi_{1}=0^{\circ}-90^{\circ}$ and $\Phi=0^{\circ}-90^{\circ}$ Euler space.

\section{Results and Discussion}

The microstructure of the steels after warm rolling consisted of elongated ferrite grains with $8.2 \pm 4.2 \mu \mathrm{m}$ and $8.7 \pm 2.9 \mu \mathrm{m}$ widths in the low- and high-Cr steels, respectively. Small amounts of pearlite $(\sim 1.1 \pm 0.6 \%)$ were also present in the microstructures. The volume fraction of grains containing in-grain shear bands was $56 \%$ for the low-Cr steel whereas it was $41 \%$ for the high-Cr steel. The evolution of texture with volume fraction recrystallized was similar for both steels (Figure 1). The strength of the ND-fiber decreases with the progress of the recrystallization. In the early stages of recrystallization, a continuous, relatively strong fiber runs from $\{112\}<110>$ to $\{111\}<112>$ with additional local maxima at $\{001\}<110>$ and $\{100\}<110>$. At the end of recrystallization, the texture consists of strong RD fibers (or, $\{110\} / / \mathrm{RD}$ ) with maxima close to $\{113\}<110>$ and to $\{001\}<110>$ in the high-Cr and low-Cr steels, respectively. The ND maxima are slightly weaker and located at $\{111\}<110>$ and $\sim\{554\}<225>$. For the high-Cr steel, it is clear that 
the ND-fiber has strengthened significantly in the $5 \%$ recrystallized sample compared to the aswarm rolled condition (Fig. 2a). Increasing the annealing time only results in a further weakening of the $\gamma$-fiber; but the intensities are slightly higher than their as-warm rolled counterparts. The evolution of the RD-fiber also indicates relative strengthening during the intermediate stages of recrystallization and reduced intensities in the fully recrystallized samples (Fig. 2b).

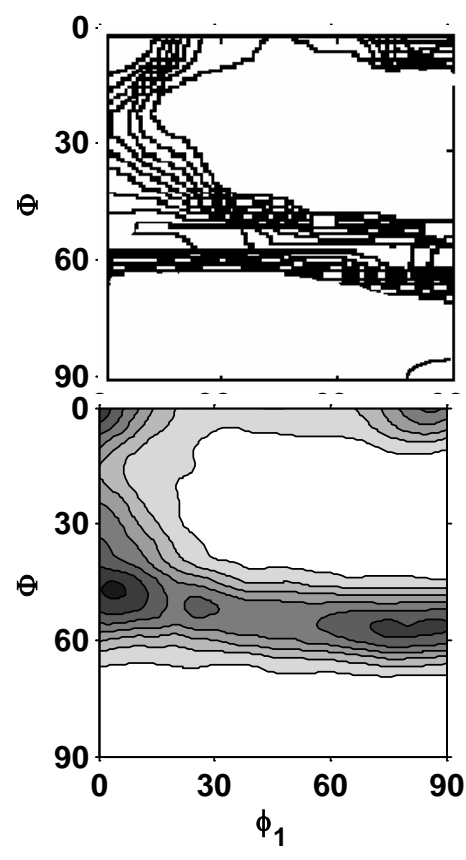

$5 \%$
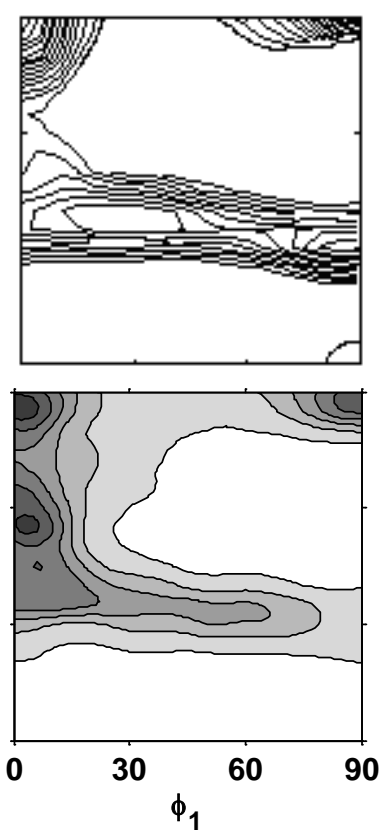

$15 \%$
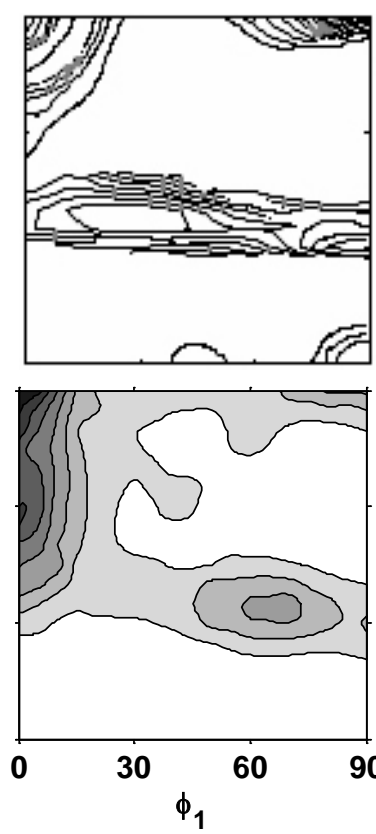

$50 \%$
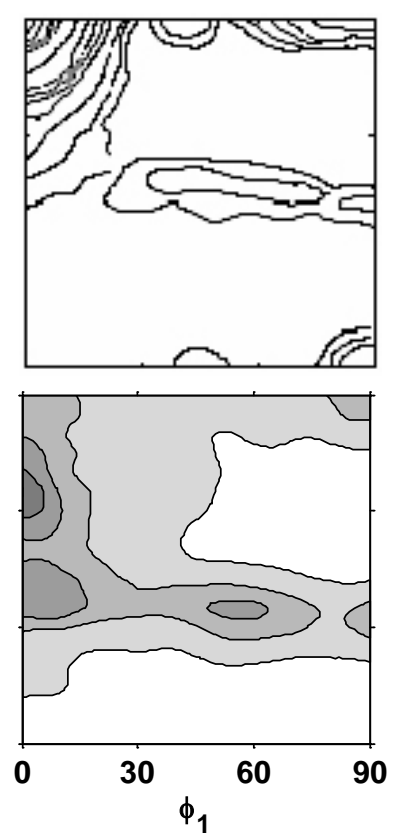

$100 \%$

Figure 1. $\phi_{2}=45^{\circ}$ ODFs showing evolution of the texture in the low-Cr (top row) and high-Cr (bottom row) steels at various stages of recrystallization. Contour levels: $1.5 \times$. Note: low-Cr textures were determined by EBSD; high-Cr, by XRD.

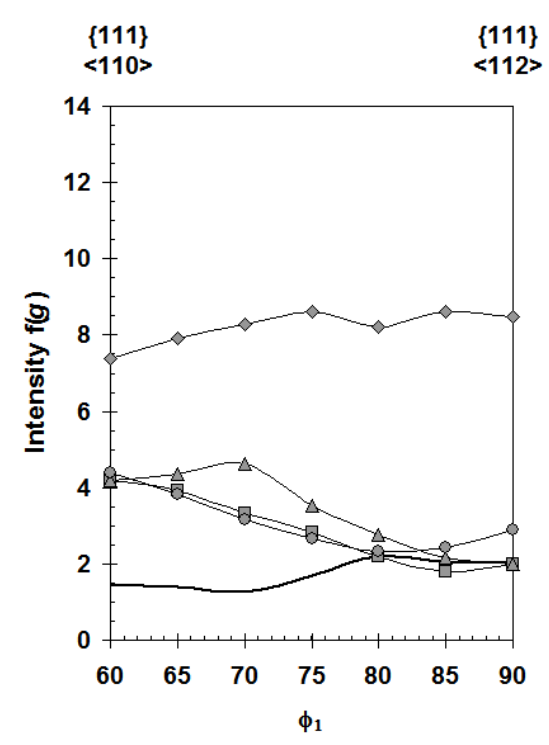

$\mathrm{a}$

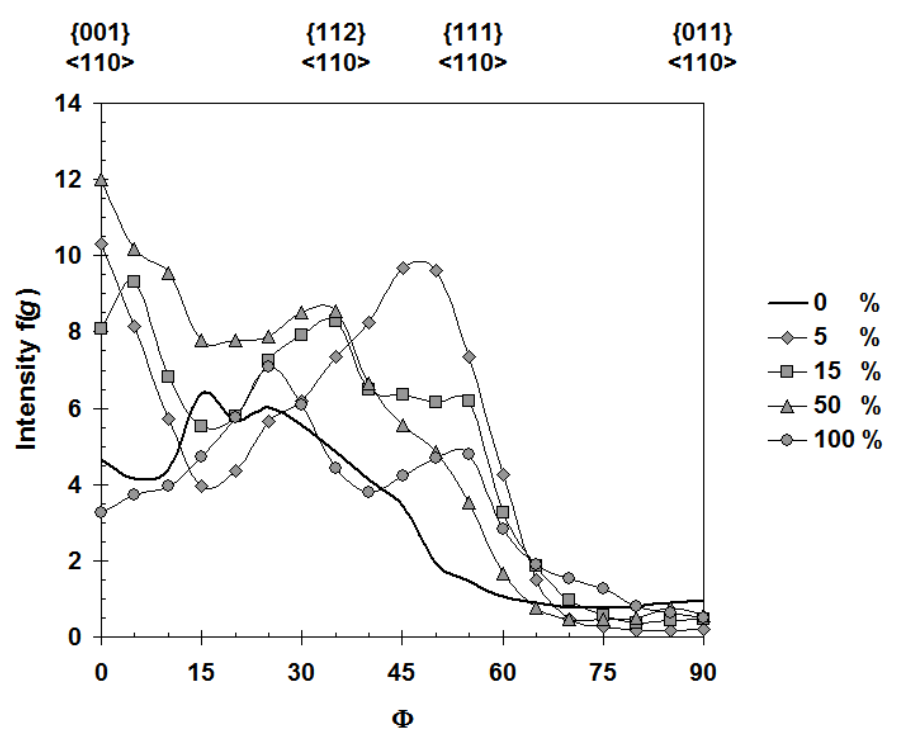

b

Figure 2. Variations in intensity of the (a) ND and (b) RD fibers of high-Cr steel at various stages of recrystallization. 
A more detailed EBSD analysis was conducted on the samples after 5\% recrystallization (Figure 3). The intensity of the ND-fiber seems to be stronger in the bulk and in the deformed grains in the low-Cr steel. The recrystallized grains display a maximum at $\{554\}<225>$ along the RD-fiber of the low-Cr steel. In the high-Cr steel, there is a continuous RD-fiber of much lower intensity. In both steels, other local maxima are at $\{001\}<110>$ and $\{100\}<110>$.

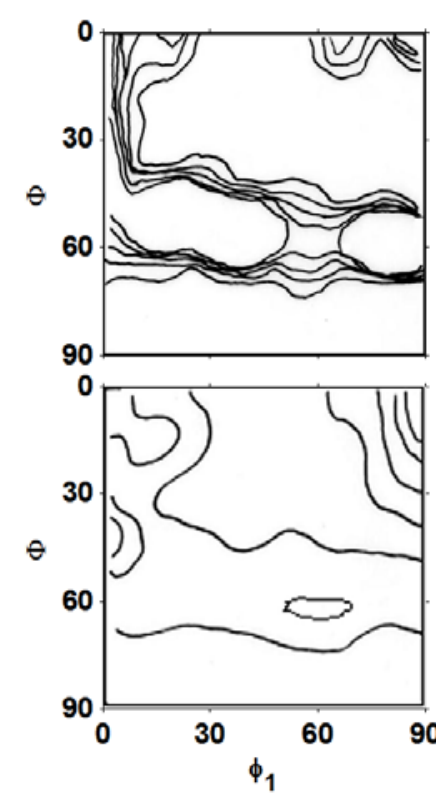

Bulk texture

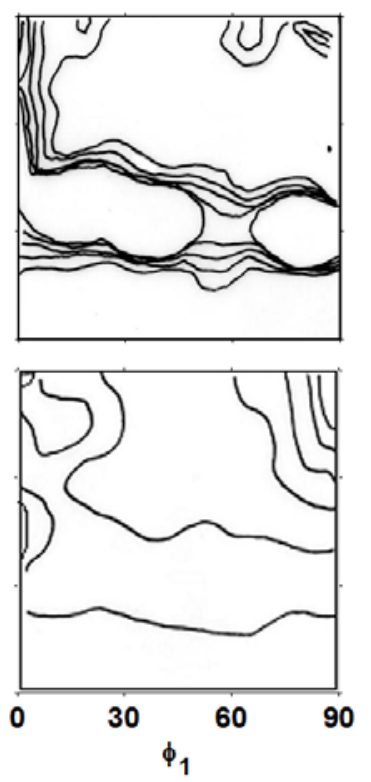

Deformed grains

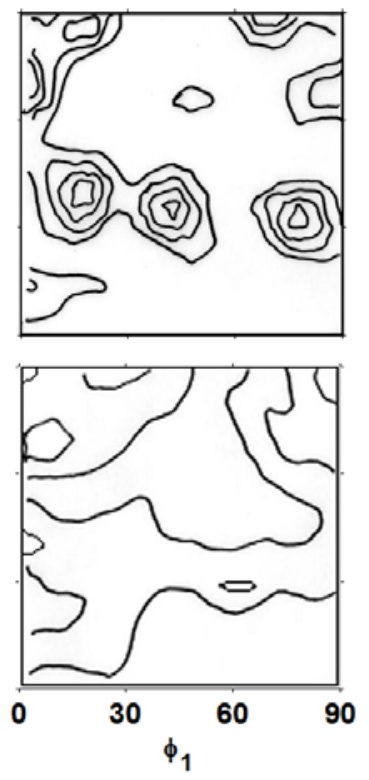

Recrystallized grains

Figure 3. Texture components at 5\% recrystallization in the low-Cr (top row) and high-Cr (bottom row) steels.

The observed differences in the positions of the maxima in the textures of the recrystallized grains during the early stages of recrystallization (Figure 3) and the 100\% recrystallized sample (Figure 1) could support the selective growth model of texture development. However, detailed studies are required to further support such a hypothesis, as work on texture evolution during the recrystallization of a warm rolled low carbon steel [10] supports the oriented nucleation model. Nonetheless, differences in the results might be due to: (i) alloying with $\mathrm{Cr}$ and (ii) the use of faster heating rates in the current work compared to the $4 \times 10^{-2} \mathrm{~K} \mathrm{~s}^{-1}$ rate used in [10]. In addition, as shown previously [7,11], the presence of fine Cr carbides affects the morphology of recrystallized grains by restricting grain boundary mobility due to pinning. The morphology of grains in fully recrystallized samples of low carbon steel is equiaxed, whereas in Cr-alloyed steels they retain an elongated shape.

Representative microstructures of samples after $5 \%$ recrystallization are shown in Figure 4 with a summary given in Tables 1 and 2. The equivalent diameters of recrystallized grains range from less than $1 \mu \mathrm{m}$ up to $8 \mu \mathrm{m}$ with slightly coarser grains in the low-Cr steel. In the present work, a $1 \mu \mathrm{m}$ limit was adopted as the boundary between a nucleus and a fully developed recrystallized grain. The common feature for both steels is that the grains nucleated at ferrite grain boundaries were larger 
than those nucleated within the grains (predominantly at the in-grain shear bands). The distribution of recrystallized grains is more uniform in the high-Cr steel. However, more grains nucleated on the in-grain shear bands in the low-Cr steel. It appears that both the lower nominal $\mathrm{C}$ content and the increase in the $\mathrm{Cr}$ level in the high-Cr steel resulted in a decreased amount of $\mathrm{C}$ in solution after warm rolling than in the low-Cr steel. Less $\mathrm{C}$ in solid solution decreases the propensity to form shear bands. This alters the balance between nucleation at shear bands and at grain boundaries. For both steels, the grain sizes of recrystallized $\gamma$-fiber grains were slightly larger than of $\alpha$-fiber grains. This might indicate a slightly faster growth rate of the former type of nuclei. As seen in Table 2, most $\alpha$ - and $\gamma$-fiber grains nucleate in deformed regions of the same orientation.
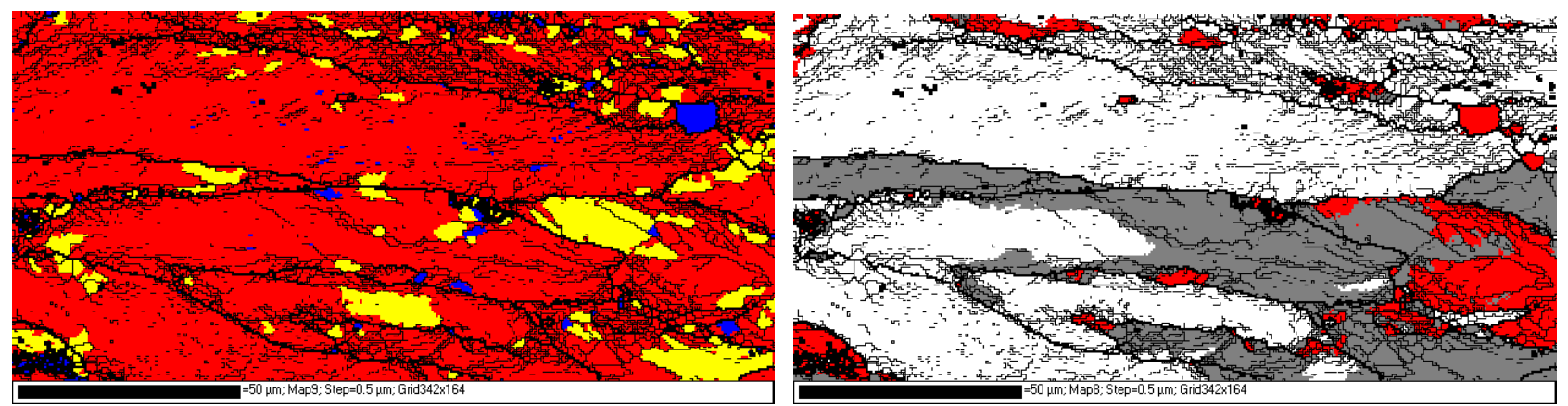

a

$\mathrm{b}$
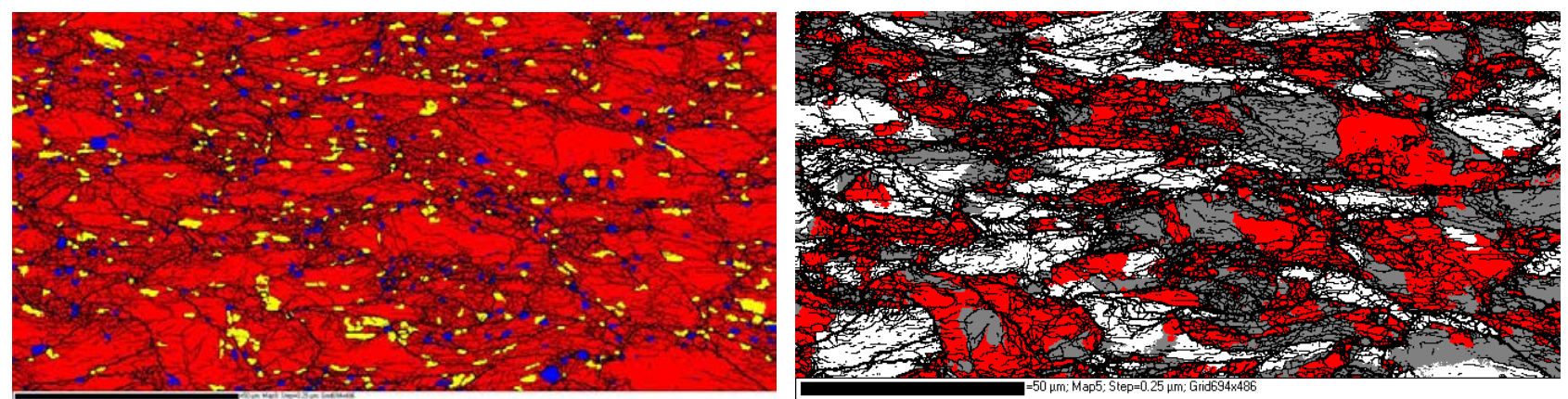

C

d

Figure 4. Locations of recrystallized (blue) and recovered (yellow) grains/subgrains in the (a) low$\mathrm{Cr}$ and (b) high-Cr steels. Thick black lines indicate high angle boundaries $\left(>15^{\circ}\right)$ and thin black lines indicate low angle boundaries $\left(<15^{\circ}\right)$. In the (b) low-Cr and (d) high-Cr (d) steels, the ND fiber is white, the RD fiber is grey, and red indicates all the other fibers

Table 1: Characterization of the samples after 5\% recrystallization.

\begin{tabular}{c|c|c|c|c|c|c|c|c}
\hline \multirow{2}{*}{ Steel } & \multicolumn{2}{|c|}{ Deformed } & \multicolumn{6}{c}{ Recrystallized } \\
\cline { 2 - 8 } & $\mathrm{V}_{\mathrm{f}}$ & $\mathrm{V}_{\mathrm{f}}$ & \multicolumn{2}{|c|}{$\gamma$-fiber } & \multicolumn{2}{|c}{$\alpha$-fiber } & \multicolumn{2}{c}{ Nucleation sites, \% } \\
\cline { 4 - 9 } & $\gamma$-fiber & $\alpha$-fiber & $\mathrm{V}_{\mathrm{f}}$ & $\mathrm{D}$ & $\mathrm{V}_{\mathrm{f}}$ & $\mathrm{D}$ & within the & at the \\
& $(\%)$ & $(\%)$ & $(\%)$ & $(\mu \mathrm{m})$ & $(\%)$ & $(\mu \mathrm{m})$ & grains & boundaries \\
\hline $0.48 \mathrm{Cr}$ & $47 \pm 16$ & $58.4 \pm 7$ & 18.4 & $2 \pm 1.5$ & 34.6 & $1.7 \pm 0.9$ & $57 \pm 5$ & $38 \pm 4$ \\
$0.78 \mathrm{Cr}$ & 28.9 & 53.3 & 23.1 & $1.7 \pm 1$ & 45.9 & $1.4 \pm 0.9$ & $29 \pm 8$ & $64 \pm 12$ \\
\hline
\end{tabular}

Legend: $\mathrm{V}_{\mathrm{f}}=$ volume fraction, $\mathrm{D}=$ equivalent grain diameter 
Table 2: Nucleus orientations after 5\% recrystallization. Calculations are based on the numbers of nuclei observed. The balance are nuclei of other orientations $(\mathrm{O})$.

\begin{tabular}{c|c|c|c|c|c|c|c|c}
\hline Steel & $\begin{array}{c}\mathrm{V}_{\mathrm{f}} \\
\gamma \text {-grains } \\
(\%)\end{array}$ & $\begin{array}{c}\mathrm{V}_{\mathrm{f}} \\
\alpha \text {-grains } \\
(\%)\end{array}$ & $\begin{array}{c}\gamma / \gamma \\
(\%)\end{array}$ & $\begin{array}{c}\gamma / \alpha \\
(\%)\end{array}$ & $\begin{array}{c}\gamma / \mathrm{O} \\
(\%)\end{array}$ & $\alpha / \alpha$ & $\alpha / \gamma$ & $\alpha / O$ \\
\hline Low-Cr & $47 \pm 2$ & $33 \pm 11$ & $68 \pm 3$ & $14 \pm 7$ & $16 \pm 9$ & $47 \pm 9$ & $22 \pm 2$ & $26 \pm 4$ \\
High-Cr & $35 \pm 7$ & $34 \pm 6$ & $41 \pm 3$ & $26 \pm 4$ & $32 \pm 3$ & $66 \pm 4$ & $10 \pm 2$ & $23 \pm 2$ \\
\hline
\end{tabular}

Legend: $\mathrm{V}_{\mathrm{f}}=$ volume fraction of grains of a particular orientation

\section{Conclusions}

Texture evolution during annealing at $710^{\circ} \mathrm{C}$ of warm rolled steels containing 0.48 and $0.78 w t \% \mathrm{Cr}$ was followed by XRD and EBSD techniques. During the early stages of recrystallization, more grains were formed at in-grain shear bands in the steel with the low $\mathrm{Cr}$ content than in the high-Cr steel. The orientations of the recrystallized grains followed those of the deformed regions. Differences between the textures of recrystallized grains after $5 \%$ recrystallization and after complete recrystallization texture give partial support to the selective growth model of texture development.

\section{Acknowledgement}

This work was supported by the Australian Research Council grant DP0663511.

\section{References}

1. R.K. Ray, J.J. Jonas and R.E. Hook: Int. Material Reviews Vol. 39 (1995), p. 129

2. $\quad$ M.R. Barnett and J.J. Jonas: ISIJ Int. Vol. 37 (1997), p. 706

3. M.R. Barnett, in Proc. Materials’98, edited by Ferry M, IMEA, Wollongong, Australia, (1998). p. 167

4. M.R. Toroghinejad, A.O. Humphreys, D. Liu, F. Ashrafizadeh, A. Najafizadeh and J.J. Jonas: Metall. Mater. Trans. A Vol. 34A (2003), p. 1163

5. P. Messien and V. Leroy: Steel Research Vol. 60 (1989), p. 320

6. A.O. Humphreys, D.S. Liu, M.R. Toroghinezhad and J.J. Jonas: ISIJ Int. Vol. 42 Supplement (2002), p. S52

7. I.B. Timokhina, J.J. Jonas and E.V. Pereloma: ISIJ Int. Vol. 45 (2005), p. 867

8. F.J. Humphreys and M. Hatherley: Recrystallization and Related Annealing Phenomena, (Pergamon/BPC Wheatons Ltd, Great Britain 1996)

9. A. Belyakov, R. Kaibyshev and T. Sakai: Metall. Mater. Trans. A Vol. 29A (1998), p. 161

10. M. Sanchez-Araiza, S. Godet, P. Jacques and J.J. Jonas: Acta Mater. Vol. 54 (2006), p. 3085

11. V. Bata: Minimizing Ageing due to Carbon in Low Carbon Sheet Steel with Aid of Mn, Cr, Mo or B Additions. PhD thesis. Monash University, Melbourne (2005) 